\title{
A spectral analysis of the myoelectric activity of the left colon in patients with schistosomiasis mansoni
}

A.A.B. Ferraz

Correspondence

\section{A.A.B. Ferraz}

Av. Beira Rio, 240, Apto. 2501

50750-400 Recife, PE

Brasil

Fax: +55-81-3271-1526

E-mail: aabf@truenet.com.br

Presented as a "Livre-Docência" thesis to the Faculdade de Medicina de Ribeirão Preto, Universidade de São Paulo, Ribeirão Preto, SP, Brazil.

Research supported by CNPq (No. 301414/97-1).

Received April 5, 2004

Accepted January 13, 2005 . . . . . . . . . . . . . .
Departamento de Cirurgia, Unidade de Transplante, Hospital das Clínicas, Universidade Federal de Pernambuco, Recife, PE, Brasil

\begin{abstract}
The objective of the present study was to perform a spectral analysis of the electrical activity of the left colon of patients with hepatosplenic schistosomiasis. Thirty patients were studied, divided into 2 groups: group A was composed of 14 patients ( 9 males and 5 females) with hepatosplenic schistosomiasis and group B was composed of 16 female patients without schistosomiasis mansoni. Three pairs of electrodes were implanted in the left colon at the moment of the surgical treatment. The signals of the electric activity of the colon were captured after postoperative recovery from the ileus and fed into a computer by means of a DATAQ data collection system which identified and captured frequencies between 0.02 and $10 \mathrm{~Hz}$. Data were recorded, stored and analyzed using the WINDAQ 200 software. For electrical analysis, the average voltage of the electrical wave in the three electrodes of all patients, expressed as millivolts $(\mathrm{mV})$, was considered, together with the maximum and minimum values, the root mean square (RMS), the skewness, and the results of the fast Fourier transforms. The average RMS of the schistosomiasis mansoni patients was $284.007 \mathrm{mV}$. During a long period of contraction, the RMS increased in a statistically significant manner from $127.455 \mathrm{mV}$ during a resting period to $748.959 \mathrm{mV}$ in patients with schistosomiasis mansoni. We conclude that there were no statistically significant differences in RMS values between patients with schistosomiasis mansoni and patients without the disease during the rest period or during a long period of contraction.
\end{abstract}

\section{Introduction}

The colon is probably the least studied and consequently the least understood segment of the gastrointestinal tract. The resulting lack of understanding of the motility pattern is directly related to the type of control which is performed in the colon. The colon suffers direct influences from myogenic factors chiefly represented by the
Key words

- Left colon

- Electromyography

- Spectral analysis

- Root mean square

- Intestinal motility

- Schistosomiasis mansoni smooth muscle covering, from neural factors involving the central nervous system and the autonomous and enteric nervous systems, and from humoral factors (1-9).

In man and other host mammals, the adult Schistosoma mansoni worms migrate to the roots of the portal system after mating. The pregnant females make their way to the smaller intestinal veins, where they lay their eggs. They may reach the submucosal veins, 
where eggs are also deposited. Eggs deposited in the vascular stretches closest to the mucosa manage to reach inside the intestine more easily (10). The permanence of the female in a submucosal vein establishes a temporary obstruction, either causing a stoppage or an inversion of the established blood currents, until the egg is eliminated $(10,11)$.

The number of retained eggs around which the granuloma develops is due to the parasite burden and the evolutionary time of the parasitemia. The collections of periovular granulomas and the spreading inflammatory process affect the muscles of the mucosa and submucosa $(10,12-19)$. As a consequence of egg retention, the submucosa becomes fibrous with parietal thickening preventing extrusion of the eggs and causing them to become fixed inside the muscle and serosa layers (10).

Experiments with laboratory mice previously infected with $S$. mansoni eggs have demonstrated an accelerated cellular reaction and the depositing of antigens around the eggs of previously sensitized animals (19). The study demonstrated sensitivity to the $S$. mansoni eggs, and showed that this sensitivity is specific, enabling transfer by cells and leading to an immunological reaction of a delayed hypersensitive nature. Areas of necrosis were also identified around the Schistosoma granulomas (19).

The development of granuloma lesions may be modified by numerous factors acting on the local deposit of immuno-complexes (13). The small intestine presents an important immunizing function, being one of the first organs affected by the disease (13).

In their experiments on mice, Catapani and Miszputen (20) detected the deposit of gamma globulin and C3 in the renal parenchyma and the development of intestinal granulomas during different stages of the disease. They also discovered a greater number of eggs in the ileum than in the jejunum. Hematoxylin-eosin staining indicated deep lesions in the ileum and the jejunum, with those of the ileum being larger. The antigen secretion of the eggs can be demonstrated by direct immunofluorescence staining, highlighting the granulomatosis reaction. During the 18th and 20th weeks, neutrophils and eosinophils were observed, the latter in greater quantity. These cells are fundamental for the destruction of eggs in tissues (20).

Schistosomiasis mansoni is a parasitic disease in which granulomas are formed around the eggs of the schistosome in the liver and the intestine. Varilek et al. (21) observed that focal granulomas destroy the enteric nerves in mice. Occasionally, neural granulomas were found, especially around the periphery of the lesions. The body of the nervous cells with granulomas presented increased sensitivity to vasoactive intestinal polypeptide. The nervous lesions varied in the two segments studied. In the distal ileum, the main lesion occurred in the myenteric plexus, while in the proximal colon it occurred in the mucosa and submucosal plexus (22). In chronic forms of schistosomiasis, the colon and the small intestine are attacked by the formation of the inflammatory granuloma $(10,13-16,21,22)$.

A lesion at the intrinsic innervation of the colon and the small intestine can result in the discontinuity of intestinal motor activity and absorptive functions (23). This damage may manifest itself as diarrhea, abdominal pain and/or constipation. The pathological alterations in the colon and the small intestine occurring in chronic schistosomiasis have not been fully determined $(15,16,24)$.

The objective of the present study was to conduct a spectral analysis of the electrical activity of the left colon in patients with hepatosplenic schistosomiasis in order to obtain an electrical pattern of the colon.

\section{Material and Methods}

The present study was conducted at the Gastrointestinal Motility Laboratory, General Surgical Unit, University Hospital, Fe- 
deral University of Pernambuco, Recife, PE, Brazil. The Ethics Committee of the University Hospital, UFPE, approved the study and the selected patients received a verbal explanation from an assistant doctor, and also signed a term of informed consent.

The study design was an observational cross-sectional case control study with a sequential comparative analysis of a group of patients with schistosomiasis and a control group without schistosomiasis.

Thirty-four patients were studied, and divided into 2 groups: group A, composed of 17 patients with hepatosplenic schistosomiasis and a history of digestive hemorrhage, and group B, composed of 17 female patients with a diagnosis of uterine myoma and an indication of total abdominal hysterectomy.

The inclusion criteria for group A patients were: over 16 years of age, a history of digestive hemorrhage, endoscopic examination of the esophageal varices, hematocrit above 22 , enzyme activity of at least $50 \%$ of the normal value, negative hepatitis test, and a hepatic biopsy confirming pure pathological schistosomiasis. The exclusion criteria were: mixed hepatopathy (schistosomiasis and hepatitis and/or another liver disease), a previous history of alcoholism, and portal vein thrombosis.

Patients were operated on an elective basis during a period with no evidence of acute digestive hemorrhage.

The surgery recommended for patients with portal hypertension schistosomiasis and a history of digestive hemorrhage was splenectomy + ligature of the left gastric vein + devascularization of the great curvature of the stomach + postoperative endoscopic sclerotherapy. Patients with deep gastric varices were submitted to gastrotomy and variceal suture in addition to splenectomy. This surgery follows the norms of the General Surgery Unit, University Hospital, UFPE.

Group B (control) consisted of patients with an ultrasound diagnosis of uterine myoma and clinical alterations represented by menstrual disturbances, hypermenorrhagia, abdominal pain, and/or abdominal tumors. All patients were submitted to the usual preoperative complementary tests as well as to preventive tests for cervical/uterine cancer (the Papanicolaou smear test). Results for neoplasia were negative for all patients.

Other factors for exclusion from both groups were: evidence of intestinal constipation, defined as less than three bowel movements per week; presence of associated diseases; routine use of medications such as laxatives, beta-blockers, calcium channel blockers, anti-depressives, tranquilizers, and other drugs that could affect intestinal motility; if classified as surgical or anesthetic risks according to categories III, IV and V of the American Society of Anesthesiology, and epidemiological positivity for Chagas' disease.

Patients were excluded while the study was in progress if they presented clinical or electromyographic suspicion that the electrode had become dislocated from its fixed position, or evidence of trans- and postoperative complications. Three group A patients were excluded from the study. One patient was excluded due to intra-abdominal bleeding on the first postoperative day. This patient was reoperated upon and bleeding was identified in the region of the diaphragm, related to spleen resection. The other two patients were excluded during the electromyographic reading on suspicion that the electrodes had dislocated. One patient in group B was also excluded from the study for the same reason.

Thus, 14 patients were analyzed in group A and 16 in group B. Group A consisted of 9 males and 5 females, with an average age of $40 \pm 9.8$ years (range: $19-56$ years). Group B was composed of female patients, with an average age of $42 \pm 8.7$ years (range: $36-62$ years).

Pre-anesthetic medication consisted of 
midazolam (an anxiolytic of the benzodiazepine group), $7.5 \mathrm{mg}$ taken orally $30 \mathrm{~min}$ prior to the beginning of the anesthetic process.

The surgical procedures for group A patients were conducted under general anesthesia. Three patients underwent a gastrotomy for variceal suture. A supra-umbilical abdominal incision was performed in 9 patients and a left subcostal incision in 5.

A total abdominal hysterectomy was performed on all patients in group B, together with unilateral annexectomy in two cases. A supra-pubic transverse incision was used for 14 patients and an infra-umbilical one in 2. Surgeries were performed under peridural anesthesia with $0.5 \%$ bupivacaine on 12 patients and under general anesthesia on the other 4.

Prophylactic antibiotics were prescribed for all patients in both groups. The choice of antibiotic as well as the duration of treatment followed the norms of the Commission of Hospital Infection Control, University Hospital, UFPE. Patients in group A received $1 \mathrm{~g}$ cefazolin intravenously for induction of anesthesia. Complementary doses were administered every $3 \mathrm{~h}$ for the duration of the surgical procedure. Antimicrobial coverage was applied during the surgical procedure only. Patients undergoing gastrotomy for surgical ligature of deep gastric varices received $500 \mathrm{mg}$ metronidazole. Prophylactic antibiotic treatment was also applied in group $B$ patients during the surgical procedure with cefazolin $(1 \mathrm{~g})$ and metronidazole $(500 \mathrm{mg})$.

Upon completion of the surgical procedure, and with no interoperative occurrences, bipolar MP-285-B, Monicrom 2-0 electrodes made of cardiovascular pacemaker wire were implanted in the taenia of the sigmoid colon $(3,7,9,25,26)$. The pacemaker wires were isolated with Teflon throughout, except for a 4-cm length at the extremities which was implanted into the taenia of the colon. Three pairs of electrodes were implanted, separated by a distance of $5 \mathrm{~cm}$, with the final pair placed at a distance of $20 \mathrm{~cm}$ from the peritoneal reflex. The electrodes were fixed at the insertion point of the colon with simple 3-0 catgut stitches. The electrodes were exposed on the left flank of the patient, and fixed to the skin with Mononylon 4-0 sutures.

After the paralytic ileum had recovered, with the patient on an unrestricted diet and discharged from the hospital, the myoelectric activity of the colon was recorded. The recording session was conducted over a period of $1 \mathrm{~h}$ after an 8 -h fast. Upon completion of data collection, the electrodes were removed by traction.

On average, data were collected from group $\mathrm{A}$ and $\mathrm{B}$ patients on the fourth postoperative day $(4.64 \pm 1.07$ and $4.12 \pm 0.67$ days, respectively). Electrical activity signals in the colon were captured and stored in the computer with the data recovery system DATAQ Series 200 (Akron, OH, USA) that identifies and captures frequencies between 0.02 and $10 \mathrm{~Hz}$. The data are recorded, stored and analyzed using the recovery software WINDAQ 200 for Windows (Akron, OH, USA).

Data were obtained using a sample of 40 points per second, which has proved to be effective for the analysis of the electric signal of the colon $(3,25)$. The intestine signal is weak and is accompanied by extraneous distorting noises, very often much louder than the actual signal itself. In order to obtain a clearer, noise-free signal, a circuit was set up with a special instrumentation amplifier as an entrance stage, thus permitting a relative gain of 1 to 1000. At this stage, a large part of the extraneous noise is generally eliminated, maintaining a balance of the impedances connected to each of the portal inverters and not to the amplifier inverters. The signal then passes through a fourth-order Butterworth filter with a cutting frequency of about 15 Hz. Thus, an improved signal is achieved, which is compatible with the characteristics of the system entrance. 
The data analysis software permits an algorithmic analysis based on the Fourier series. The program uses fast Fourier transform to depurate and analyze the data. The fast Fourier transform program has a resolution of 0.23 cycles $/ \mathrm{min}$. When the procedure is carried out, the electrical control activity (ECA) and electrical response activity (ERA) are separated. Frequencies below $0.3 \mathrm{~Hz}$ are selected for ECA analysis, while frequencies between 0.7 and $10 \mathrm{~Hz}$ are selected for ERA analysis.

From the ECA analysis it was possible to determine the dominant frequencies and their respective percentages. The dominant frequency is that which presents the largest magnitude. The dominant frequency during each minute was classified as follows: low (0-9 cycles/min), medium ( $>9-15$ cycles/min) and high (above 15 cycles/min). In the ERA analysis, the signal should last for a minimum of $>0.6 \mathrm{~s}$ with an average amplitude greater than the baseline value. The beginning and end of the period, and the duration of each ERA were classified as short $(<6.7 \mathrm{~s})$ or long ( $>6.7 \mathrm{~s})$. The migrating motor complex was considered as the appearance of a long-duration contraction, or groups of longduration contractions, at a minimum of two electrode sites, at different times.

In the analysis of the intestinal electrical activity, the average tension of the electrical wave of the three electrodes, expressed in millivolts $(\mathrm{mV})$, was considered for all patients, as well as the maximum and minimum values, the variance, the root mean square (RMS), the skewness, and the result of the Fourier transform. The RMS is expressed in $\mathrm{mV}$ and determines the effective tension of the electrical wave, while the skewness, also expressed in $\mathrm{mV}$, determines the degree of asymmetry in the electrical wave.

Tests were conducted with a signal simulator after introducing signals of known characteristics. Contractions that began simultaneously and had the same duration, amplitude and characteristics in all electrodes were considered to be artifact contractions and the data were discarded. The size of the sample was determined by statistical methods. The number of 14 patients in group A and 16 patients in group B proved to be suitable for the objective of the study (to perform a spectral analysis of the electrical activity of the left colon of patients with hepatosplenic schistosomiasis).

Analysis of variance was applied to the data for each group separately in order to demonstrate if the resulting numerical data presented a Gaussian distribution. The Student $t$-test was then applied to the independent samples, with the level of significance set at $\mathrm{P}<0.05$.

\section{Results}

No deaths due to the methodology or to the surgical procedure were recorded among the 34 patients studied. One patient in group A presented intra-abdominal bleeding originating from the abdominal border of the diaphragm, around the region of the splenic bed. Of the 17 patients in group A, only 2 presented complications related to the methodology employed. One presented a small hematoma on the left flank, while the other complained of intense pain during electrode removal. The patient with the hematoma had evolved satisfactorily by the 15 th postoperative day. Only one patient in group B complained of pain during electrode removal.

The surgical time needed for electrode placement was $10.1 \pm 3.2$ min for group A and $9.8 \pm 2.8 \mathrm{~min}$ for group B. This difference was not statistically significant (Student $t$-test).

Among the qualitative variables considered to be confounding factors, no statistically significant difference was recorded within the studied groups regarding surgical or anesthetic risk classification by the American Society of Anesthesiology and age.

The spectral analysis of the patients is shown in Table 1 . No statistically significant 
Table 1. Spectral analysis of the myoelectric activity of the left colon.

\begin{tabular}{lcc}
\hline Spectral analysis & $\begin{array}{c}\text { Group A } \\
\text { (14 patients) }\end{array}$ & $\begin{array}{c}\text { Group B } \\
\text { (16 patients) }\end{array}$ \\
\hline Mean voltage $(\mathrm{mV})$ & 79.112 & 57.049 \\
Standard deviation $(\mathrm{mV})$ & 169.596 & 163.498 \\
Voltage - mean minimum value $(\mathrm{mV})$ & -840.42 & -1266.39 \\
Voltage - mean maximum value $(\mathrm{mV})$ & 1262.16 & 1303.993 \\
Voltage - variance $(\mathrm{mV})$ & 28.762 & 26.731 \\
RMS $(\mathrm{mV})$ & 284.007 & 220.828 \\
Skewness (mV) & 118.896 & 54.683 \\
Voltage - area (volt) & 328.3474 & 185.898 \\
Fourier transform $(\mathrm{Hz})$ & 1.091706 & 1.099009 \\
\hline
\end{tabular}

Group $A$ = shistosomotic patients; Group B = hysterectomy patients.

RMS = root mean square

There were no statistically significant differences between the groups (Student $t$ test).

Table 2. Analysis of the electrical activity of the left colon.

\begin{tabular}{lcc}
\hline Electrical activity & $\begin{array}{c}\text { Group A } \\
\text { (14 patients) }\end{array}$ & $\begin{array}{c}\text { Group B } \\
\text { (16 patients) }\end{array}$ \\
\hline Low-frequency ECA (\%) & $96.7 \%$ & $98.0 \%$ \\
Short-duration ERA (number/h $\pm \mathrm{SD}$ ) & $86.6 \pm 12.6$ & $98.6 \pm 17.3$ \\
Short-duration ERA (s $\pm \mathrm{SD})$ & $2.13 \pm 0.99^{*}$ & $2.30 \pm 0.30$ \\
Long-duration ERA (number/h $\pm \mathrm{SD})$ & $5.6 \pm 3.98$ & $8.1 \pm 3.20$ \\
Long-duration ERA (s $\pm \mathrm{SD})$ & $12.57 \pm 3.75^{*}$ & $11.30 \pm 0.39$ \\
Migrant motor complex (number/h $\pm \mathrm{SD})$ & $2.8 \pm 1.1$ & $0.8 \pm 0.6$
\end{tabular}

Group A = shistosomotic patients; Group B = hysterectomy patients. $E C A$ = electrical control activity; $E R A=$ electrical response activity. ${ }^{*} \mathrm{P}<0.05$ compared to group B (Student $t$-test).

Table 3. Spectral analysis of long-duration electrical response activity in the left colon

\begin{tabular}{lcc}
\hline Spectral analysis & $\begin{array}{c}\text { Group A } \\
\text { (79 contractions) }\end{array}$ & $\begin{array}{c}\text { Group B } \\
\text { (129 contractions) }\end{array}$ \\
\hline Mean voltage (mV) & $90.364^{*}$ & 303.745 \\
Standard deviation (mV) & 247.703 & 372.912 \\
Voltage - mean minimum value $(\mathrm{mV})$ & -332.678 & -1050.039 \\
Voltage - mean maximum value $(\mathrm{mV})$ & 1149.618 & 855.619 \\
Voltage - variance $(\mathrm{mV})$ & $61.356^{*}$ & 139.063 \\
RMS $(\mathrm{mV})$ & 748.959 & 487.950 \\
Skewness $(\mathrm{mV})$ & -75.449 & 12.435 \\
\hline
\end{tabular}

Group A = shistosomotic patients; Group B = hysterectomy patients.

RMS = root mean square.

${ }^{*} \mathrm{P}<0.05$ compared to group B (Student $t$-test). difference was detected between group A and group B. ECA was present at each moment of each reading of each patient in both groups, and was predominantly of low frequency. No statistical difference was identified between the two groups studied (Table 2).

Analysis of short-duration ERA showed no differences between groups regarding the number of contractions. Group A patients (with schistosomiasis) presented an average of $86.6 \pm 12.6$ contractions, with an average duration of $2.13 \pm 0.99 \mathrm{~s}$. Patients in group B (without schistosomiasis) presented an average of $98.6 \pm 17.3$ contractions, with an average duration of $2.3 \pm 0.3 \mathrm{~s}$. The length of short-duration contractions was significantly longer in group B patients than in group A patients (Table 2).

The electrical response activity of longduration contractions did not differ between groups when the number of contractions were analyzed. However, once again the duration of contractions was significantly different. The long-duration contractions of the group A patients (with schistosomiasis) lasted longer than those of the patients in group B (Table 2). Within the two groups, no differences were recorded in the number of migrating motor complexes (Table 2).

Table 3 illustrates the spectral analysis of the long-duration contractions in both groups. Seventy-nine long-duration contractions in group A and 129 in group B were analyzed. The average voltage of group B patients was significantly higher than that of group A patients (Table 3 ).

The RMS of groups A and B are presented in Table 4. Three reading periods were stratified: of the global average of the electrical reading of the three electrodes; of the long-duration contractions, and of the periods during which no contractions occurred (denoted rest period). Statistical comparison of the three periods inside group $\mathrm{A}$ and inside group B showed significant differences. When groups A and B were com- 
pared, no statistical differences were identified.

\section{Discussion}

The limited knowledge of the physiology and physiopathology of the functional afflictions that attack the colon may be related to the difficulties in obtaining reliable recordings of the motor and electrical activity of the large intestine $(25,27-30)$. The use of bipolar electrodes permits a better understanding of the data collection process, consequently improving its interpretation.

The bipolar electrode captures the electrical activity between the electrodes. The sense of this activity determines the positivity or negativity of the signal, or rather, a determined activity is positive because that electric wave has traveled from electrode 1 to electrode 2. Should a new electric wave travel in the opposite direction (electrode 2 to electrode 1), this electric wave would be represented in the graph as a negative wave. Thus, the interpretation of the electrical activity of a determined segment of the intestine using bipolar electrodes and simply analyzing the average voltage may be inadequate.

The average voltage, in $\mathrm{mV}$, was 79.112 $\pm 169.596 \mathrm{mV}$ for the patients with schistosomiasis, and $57.049 \pm 163.498 \mathrm{mV}$ for group B patients. This wide variation, characterized by a standard deviation greater than twice the average value, illustrates this problem very well. Electrical activity ranged from -840.42 to $1262.16 \mathrm{mV}$ in group $\mathrm{A}$, and from -1266.39 to $1303.993 \mathrm{mV}$ in group B. The contraction represented by the value of $-1266.39 \mathrm{mV}$ represented a contractility, a strength, similar to 1303.993, differing only in the way in which it was carried out.

The use of the RMS seemed more appropriate. The RMS determines the effective tension of an electric wave, and its formula uses the square root analysis of the average quadratic signal, thus eliminating the inconvenience of the negativity of the signal. In practice, RMS determines the energy of the signal, or rather, the strength of a contraction. On this basis, RMS is used to analyze the electric signal of the activity of the left colon. In Table 4, the RMS is analyzed in three different situations: the overall average of the signal during the entire reading period, during the long duration contraction periods and during the rest periods, during which contractions were not identified. The result of this analysis demonstrated that the electrical activity of the left colon presented a variation of five to six times between one contraction and the rest period. In other words, in group A (patients with schistosomiasis) the average electric reading was

Table 4. Root mean square analysis, in millivolts, during contractions and rest period of the electrical activity of the left colon.

\begin{tabular}{lrrrrrrrr}
\hline \multirow{2}{*}{$\begin{array}{l}\text { Patient } \\
\text { No. }\end{array}$} & \multicolumn{3}{c}{ Group A } & & \multicolumn{3}{c}{ Group B } \\
\cline { 2 - 5 } \cline { 6 - 8 } & Rest & Contraction & Mean & & Rest & Contraction & Mean \\
\hline & & & & & & & & \\
1 & 216.860 & 655.680 & 378.220 & & 63.972 & 143.100 & 128.630 \\
2 & 137.390 & 2368.200 & 166.340 & & 146.620 & 1084.700 & 346.300 \\
3 & 97.671 & 682.380 & 431.320 & & 78.252 & 1869.900 & 165.550 \\
4 & 376.400 & 5158.510 & 427.800 & & 25.051 & 59.007 & 57.094 \\
5 & 200.690 & 804.410 & 254.800 & & 61.946 & 251.450 & 130.070 \\
6 & 125.480 & 299.530 & 164.750 & & 55.198 & 95.700 & 86.606 \\
7 & 87.220 & 196.710 & 112.590 & & 93.993 & 965.000 & 713.210 \\
8 & 57.109 & 284.950 & 164.300 & & 61.210 & 138.600 & 75.634 \\
9 & 71.289 & 623.170 & 252.740 & & 102.290 & 292.360 & 149.580 \\
10 & 53.191 & 1070.000 & 683.310 & & 108.010 & 318.840 & 252.650 \\
11 & 8.379 & 716.190 & 362.470 & & 151.680 & 476.500 & 332.380 \\
12 & 93.338 & 1.4092 & 193.920 & & 175.250 & 510.240 & 265.950 \\
13 & 15.469 & 227.330 & 87.792 & & 90.512 & 384.060 & 353.160 \\
14 & 243.880 & 632.160 & 295.750 & & 59.792 & 224.720 & 68.334 \\
15 & & & & & 169.290 & 589.490 & 259.340 \\
16 & & & & & 70.373 & 403.530 & 148.760 \\
Mean & 127.455 & 748.959 & 284.007 & & 94.590 & 487.950 & 220.828 \\
SD & 76.85 & 379.425 & 124.975 & & 35.700 & 322.448 & 122.149 \\
\hline
\end{tabular}

Group A = shistosomotic patients; Group B = hysterectomy patients

Data are reported in millivolts.

Statistical analysis (Student $t$-test):

$$
\text { Group A Group B }
$$

Rest vs contraction: $\quad P=0.001345 \quad P=0.004357$

Rest vs mean: $\quad P=0.0055 \quad P=0.009037$

Mean vs contraction: $P=0.01039 \quad P=0.044877$

Group A rest vs group B rest: nonsignificant

Group A contraction vs group B contraction: nonsignificant

Group A mean vs group B mean: nonsignificant 
$284.007 \pm 124.975 \mathrm{mV}$, reaching $748.959 \pm$ $379.425 \mathrm{mV}$ during the long-duration contractions and about $127.455 \pm 76.85 \mathrm{mV}$ during the rest periods. When one result is compared with the other, these values were found to be significantly different. In group B (hysterectomy patients without schistosomiasis and considered to be a group of normal patients), the average reading was $220.828 \pm 122.149 \mathrm{mV}$, reaching $487.950 \pm$ $322.448 \mathrm{mV}$ in the long-duration contractions and returning to $94.590 \pm 35.700 \mathrm{mV}$ during the rest periods. These values were significantly different.

When the values of group A were compared with those of group B, no statistical differences were identified.

The skewness analysis provides an indication of the asymmetry of the sample. The electrical analysis of the colon demonstrated large asymmetry in the two groups. This fact corroborates the defining data of a myoelectrical pattern in the colon. The colon does not present defined patterns, either motor or electrical. However, this property acts as a reinforcement of the function of the colon. The primordial function of the colon is absorption, and for this it is necessary to maintain the food in contact with the mucosa for the longest time possible. The propulsive function should be slow, gradual and performed in such a manner that it creates an effective mixture of the stools. Migratory contractions are identified in the distal and retrograde sense.

The motor analysis presented in Table 2 demonstrated the presence of ECA at all moments of the analysis. This has already been reported in the literature and it is generally accepted that ECA is omnipresent in the colon $(3,6,7,9,18,25-28,30)$. ECA frequency was predominantly low; $86.6 \pm 12.6$ shortduration contractions per hour were identified in group A and 98.6 \pm 17.3 short-duration contractions per hour were identified in group B. A statistically significant difference was identified in relation to the dura- tion of these contractions. The patients without schistosomiasis (group B) presented a significantly longer duration than patients with schistosomiasis (group A).

The number of long-duration contractions was $5.6 \pm 3.98$ per hour in group $\mathrm{A}$ and as $8.1 \pm 3.2$ in group B. Once again, a significant difference was detected in the analysis of these contraction, with the long-duration contractions of group A being longer that those of group B.

The number of long-duration migratory contractions, on the other hand, represented by the migrating motor complex, was $2.8 \pm$ 1.1 in group A and $0.8 \pm 0.6$ in group B. The migrating motor complex represents the propulsion of food. Such a complex could have a distal sense, in the direction of the rectum, and a retrograde sense. The migrating motor complex was only analyzed in the distal sense. This small number confirms the predominance of absorption in the colon.

Table 3 presents the analysis of the longduration contractions identified in the readings of all patients. A total of 79 contractions were analyzed in the patients with schistosomiasis and 129 in the group without schistosomiasis. A statistically significant difference was identified regarding the average voltage and variance. Group B patients presented a significantly higher voltage than group A patients. This fact was not confirmed by the RMS, which led us to believe that the voltage of group B presented a lower variation between the positive and the negative and thus, the average was statistically higher. This interpretation is reinforced by the skewness value which in group B was well below that of group A.

The use of the Fourier transform enables the identification of an electric spectrum of signal segments (periods of $1 \mathrm{~min}$ ), called data blocks, of each isolated electrode. The unit of these data blocks permits a credible analysis of the electrical alterations obtained, thus permitting the stratification of the type of wave to be analyzed $(25,28,31)$. 
The Fourier series is a mathematical technique that describes an aperiodic wave. This method supplies a spectrum with the duration and frequency of an electrical wave. Using the Fourier transform it is possible to stratify the data obtained using 512 points per minute, thus analyzing the ECA and the ERA. The Fourier transform is often used in the analysis and interpretation of electrical data, particularly myoelectrical data of the gastrointestinal tract, facilitating data handling.

The ERA was considered to be of short duration when it lasted less than $6.7 \mathrm{~s}$, since this is the maximum length of a contraction that occurs within a low frequency ECA (60 $\mathrm{s} / 9 \mathrm{cpm}=6.7 \mathrm{~s} / \mathrm{c})(25,27,30,32,33)$.

The characterizing of the electrical activity of the colon is a fundamental step in the correction of intestinal problems that modify and alter colonic function. The understanding of the type of electric activity and its characteristics are determined in the control and cure of functional diseases of the colon.

Acting on the electric current of the colon and the other organs of the gastrointestinal tract could be the missing stage in the understanding of the physiopathological phenomenon of many motor alterations in the colon and could represent the beginning of great advances in the treatment of complex problems related to this organ and to the reduction of the period of the paralytic ileum, as well as the resolution of complications related to chagasic and idiopathic megacolon, of motor alterations of the colon in diabetic patients, or even of problems of chronic diarrhea and constipation (27).

The knowledge of the electrical characteristics of the colon resulting from this study, in which two groups of patients were studied, is one more stage in this line of research, in which electromyographic alterations of the colon are studied. The knowledge gained about the electrical components with the aim of accelerating or decreasing the intestinal movement is a field of medicine little explored. The difficult interpretation of the myoelectric data, as well as the lack of definition of an electrical pattern in the colon, may have led to inadequate or premature interpretations, which have resulted in this sparse knowledge of the electrical alterations of the large intestine.

It is believed that a search for, and a definition of an electrical pattern of the colon should be a fundamental step in the clinical handling of physiopathological alterations of the colon.

We conclude that there was no statistically significant difference in RMS values between patients with and without schistosomiasis mansoni, either during the rest period or during long-duration contractions.

\section{References}

1. Sellin JH (1988). Physiology of digestion and absorption. In: Miller TA (Editor), Physiologic Basis of Modern Surgical Care. C.V. Mosby Company, Washington, DC, USA, 330

2. Ferraz $A A B$ (2002). Análise espectral da atividade mioelétrica do cólon esquerdo: avaliação em pacientes com e sem esquistossomose mansônica. "Livre Docente" thesis, Faculdade de Medicina de Ribeirão Preto, Universidade de São Paulo, Ribeirão Preto, SP, Brazil.

3. Ferraz AAB, Bacelar TS, Santos Jr MA, Vasconcelos HG, Figueiredo FL, Vaeiredo FL, Vasconcelos HMC \& Ferraz EM (1995). Atividade mioelétrica do cólon: descrição de metodologia. Revista Brasileira de Colo-Proctologia, 15: 114-121

4. Ferraz AAB, Cowles VE, Schulte WJ \& Condon RE (1994). Intraluminal perfusion catheter versus serosal transducer for recording co-
Ionic contractile activity. Gastroenterology, 106: A498 (Abstract).

5. Ferraz AA, Cowles VE, Condon RE \& Schulte WJ (1995). Opioid and nonopioid analgesic drug effects on colon contractions in monkeys. Digestive Diseases and Sciences, 40: 1417-1419.

6. Ferraz AA, Cowles VE, Condon RE, Carille S, Ezberci F, Frantzides CT \& Schulte WJ (1995). Nonopioid analgesics shorten the duration of postoperative ileus. American Surgeon, 61: 1079-1083.

7. Ferraz AAB, Lima FEB, Santos Jr MA, Ferraz EM, Mathias CAC, Lins MHA \& Vieira RM (1998). Gastrocolonic electrical response of colon in patients with hepatosplenic mansonic schistosomiasis. Arquivo Brasileiro de Cirurgia Digestiva, 13: 31-36.

8. Ferraz AAB \& Mathias CAC (1999). Avaliação experimental da recuperação do íleo paralítico pós-operatório após colectomia convencional e laparoscópica. Revista do Colégio Brasileiro de 
Cirurgiões, 26: 359-365.

9. Ferraz AAB, Silveira RK, Mota CVA, Kitner D, Barreto FRS \& Silveira MJC (1998). Efeito da morfina epidural na atividade eletromiográfica do cólon esquerdo durante a recuperação do íleo paralítico pósoperatório. Anais da Faculdade de Medicina da Universidade Federal de Pernambuco, 43: 27-36.

10. Coelho RB (1965). Aspectos da esquistossomose mansônica. II. Comportamento patogênico do ovo no intestino. Anais da Faculdade de Medicina da Universidade Federal de Pernambuco, 16: 121126.

11. Andrade AZ \& Silveira GM (1990). Schistosomotic intestinal. Gastroenterologia e Endoscopia Digestiva, 9: 158 (Abstract).

12. David HS, Kenneth SW \& Adel AFM (1979). Morbidity in schistosomiasis mansoni in relation to intensity of infection: study of a community in Kisumu, Kenia. American Journal of Tropical Medicine and Hygiene, 26: 220-229.

13. Domingo EO \& Warren KS (1969). Pathology and pathophysiology of the small intestine in murine schistosomiasis, including a review of the literature. Gastroenterology, 56: 231-240.

14. Durak DT, Ackerman SJ, Loegerino DA \& Gleich GJ (1981). Purification of human eosinophil-derived neurotoxin. Proceedings of the National Academy of Sciences, USA, 78: 5165-5169.

15. Fedail SS \& Gadir AFMA (1985). The pathology of the small intestine in human schistosomiasis mansoni in the Sudan. Tropical Medicine and Parasitology, 36: 94-96.

16. Gelfand M \& Ross WF (1953). The distribution of schistosome ova in the alimentary tract in subjects of bilharziasis. Transactions of the Royal Society of Tropical Medicine and Hygiene, 47: 215-217.

17. Cline $B L$, Rymzo WT, Hiatt RA, Knight WB \& Rerrios-Duran LA (1977). Morbidity from schistosomiasis mansoni in a Puerto Rican community: a population based study. American Journal of Tropical Medicine and Hygiene, 26: 109-117.

18. Sarna SK, Waterfall WE, Bardakjian BL \& Lind JF (1981). Types of human colonic electrical activities recorded post-operatively. Gastroenterology, 81: 61-70.

19. Silveira AC (1989). Controle da esquistossomose no Brasil. Memórias do Instituto Oswaldo Cruz, 84 (Suppl I): 91-104.

20. Catapani WR \& Miszputen SJ (1985). Murine schistosomiasis mansoni: estimation of some immunohistological parameters of small bowel granulomas and renal parenchyma. Arquivos de Gastroenterologia, 22: 176-181.

21. Varilek GW, Weinstoek JW, Williams TH \& Jew J (1991). Alterations of the intestinal innervation in mice infected with Schistosoma mansoni. Journal of Parasitology, 77: 472-478.

22. Warren KS, Domingo EO \& Cowan RBT (1967). Granuloma formation around schistosome eggs as a manifestation of delayed hypersensitivity. American Journal of Pathology, 51: 735-756.

23. Amorim AG (1988). Dados histológicos gerais morfométricos e funcionais da mucosa do intestino delgado na forma hepatoesplênica da esquistossomose mansônica. Master's thesis, Universidade Federal de Pernambuco, Recife, PE, Brazil.

24. Koppisch E (1941). Studies on schistosomiasis mansoni in Puerto Rico. VI. Morbid anatomy of the disease as found in Puerto Ricans. Puerto Rican Journal of Public Health and Tropical Medicine, 16: 395-455.

25. Condon RE, Cowles VE, Ferraz AA et al. (1995). Human colonic smooth muscle electrical activity during and after recovery from postoperative ileus. American Journal of Physiology, 269 (Part 1): G408-G417.

26. Ferraz AA, Wanderley GJ, Santos Jr MA, Mathias CA, Araujo Jr JG \& Ferraz EM (2001). Effects of propanolol on human postoperative ileus. Digestive Surgery, 18: 305-310.

27. Sarna SK (1991). Physiology and pathophysiology of colonic motor activity. Part one of two. Digestive Diseases and Sciences, 36: $827-$ 862.

28. Sarna SK, Bardakjian BL, Waterfall WE \& Lind JF (1980). Human colonic electrical activity (ECA). Gastroenterology, 78: 1526-1536.

29. Sarna SK (1991). Physiology and pathophysiology of the colonic motor activity. Part two of two. Digestive Diseases and Sciences, 36: 998-1018.

30. Condon RE, Frantzides CT, Cowles V, Mahoney S, Schulte WJ \& Sarna SK (1986). Resolution of postoperative ileus in humans. Annals of Surgery, 203: 574-581.

31. Sunshine AG, Perry R, Reynolds JC, Cohem S \& Ouyang A (1989). Colonic slow wave analysis: limitations of usefulness of fast Fourier transform (FFT). Digestive Diseases and Sciences, 34: 1173-1179.

32. Frantzides CT, Cowles V, Salaymeh B, Tekin E \& Condon RE (1992). Morphine effects on human colonic myoelectric activity in the postoperative period. American Journal of Surgery, 163: 144-149.

33. Ferraz AAB (1994). Atividade mioelétrica do cólon: Avaliação experimental e clínica do ketorolac tromethamine, durante e após a recuperação do íleo paralítico pós-operatório. Anais da Faculdade de Medicina da Universidade Federal de Pernambuco, 5: 47-56. 